\title{
Intrinsic stress evolution during amorphous oxide film growth on Al surfaces
}

\author{
D. Flötotto, ${ }^{1, a)}$ Z. M. Wang, ${ }^{1}$ L. P. H. Jeurgens, ${ }^{1, b)}$ and E. J. Mittemeijer ${ }^{1,2}$ \\ ${ }^{1}$ Max Planck Institute for Intelligent Systems (former Max Planck Institute for Metals Research), \\ Heisenbergstraße 3, D-70569 Stuttgart, Germany \\ ${ }^{2}$ Institute for Materials Science, University of Stuttgart, Germany
}

(Received 14 November 2013; accepted 18 February 2014; published online 4 March 2014)

\begin{abstract}
The intrinsic stress evolution during formation of ultrathin amorphous oxide films on $\mathrm{Al}(111)$ and $\mathrm{Al}(100)$ surfaces by thermal oxidation at room temperature was investigated in real-time by in-situ substrate curvature measurements and detailed atomic-scale microstructural analyses. During thickening of the oxide a considerable amount of growth stresses is generated in, remarkably even amorphous, ultrathin $\mathrm{Al}_{2} \mathrm{O}_{3}$ films. The surface orientation-dependent stress evolutions during $\mathrm{O}$ adsorption on the bare $\mathrm{Al}$ surfaces and during subsequent oxide-film growth can be interpreted as a result of (i) adsorption-induced surface stress changes and (ii) competing processes of free volume generation and structural relaxation, respectively. (C) 2014 AIP Publishing LLC.
\end{abstract}

[http://dx.doi.org/10.1063/1.4867471]

Thin (native) oxide films are formed spontaneously on most metallic surfaces under ambient conditions. Although the thickness of such a surficial oxide film is typically less than $10 \mathrm{~nm}$, it governs many important properties of the oxidized material system, such as the electronic conductivity, adhesion, wetting, friction, wear, and corrosion resistance. ${ }^{1-3}$

The formation of a thin oxide film on a metal surface upon exposure to an oxidizing atmosphere involves a series of competing and overlapping steps, including physisorption of $\mathrm{O}$ molecules, dissociative $\mathrm{O}$ chemisorption, oxide nucleation, and oxide-film growth. As soon as the entire substrate surface is covered by a laterally closed oxide film, further oxide-film growth is limited by the transport of the reactant species through the oxide film. At low temperatures (say, $T<600 \mathrm{~K}$ ), this transport is driven by a surface-charge field due to the socalled kinetic potential, which builds up between the metal substrate and (charged) chemisorbed oxygen species on the oxide surface. ${ }^{4-7}$ The surface-charge field strength linearly decreases with increasing oxide-film thickness and as a result, at the low temperatures considered, the formed oxide films exhibit near-limiting thicknesses $(<10 \mathrm{~nm})$.

For many metals, such as $\mathrm{Al}, \mathrm{Si}$, and $\mathrm{Zr}$, the initial formation of an amorphous (am) instead of a crystalline oxide film is (thermodynamically) preferred. ${ }^{8,9}$ Such amorphous oxide films are often considered to be stress free. ${ }^{10,11}$ No intrinsic stresses due to lattice mismatch can arise between a crystalline substrate and an amorphous thin film. Furthermore, amorphous oxides are characterized by a large amount of free volume ${ }^{12}$ and a high bond flexibility, which facilitate relaxation of (applied) stresses at relatively low temperatures. $^{11}$

In contrast with the above general suppositions, this study reveals that a significant intrinsic stress can arise in the amorphous oxide film formed on a bare Al metal surface during oxidation at room temperature. Such intrinsic growth stresses in (amorphous) oxide films can strongly affect the

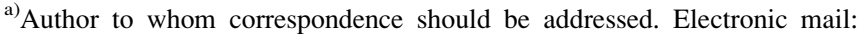
d.floetotto@is.mpg.de

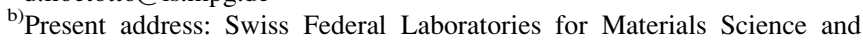
Technology, Überlandstrasse 129, 8600 Dübendorf, Switzerland.
}

mechanical, chemical, electronic, and/or optical properties of the material and can thus play a crucial role in technologies such as microelectronics and functional metal surfaces in catalysis, coating, and biomedical applications. Up to date, no experimental investigations on the development of stress in ultrathin amorphous oxide films forming on metal surfaces have been reported. Only the intrinsic stress evolutions of much thicker (in the micrometer range), crystalline oxide films on metals and alloys have been studied for thermal oxidation at elevated temperatures. ${ }^{13-15}$

All experiments were carried out in a custom-designed ultrahigh vacuum (UHV) system (base pressure $<1 \times 10^{-8} \mathrm{~Pa}$ ) for thin-film deposition by thermal evaporation, in-situ Angle-Resolved X-ray Photoelectron Spectroscopy (AR-XPS), and thermal oxidation. Single crystalline $\mathrm{Al}(111)$ and $\mathrm{Al}(100)$ films (with thicknesses $>60 \mathrm{~nm}$ ) were epitaxially grown, by thermal evaporation, on $100 \mu \mathrm{m}$ thin, clean $\operatorname{Si}(111)$ and $\operatorname{Si}(100)$ wafers, respectively (note: a $\operatorname{Ag}(100)$ buffer layer on $\mathrm{Si}(100)$ was used to establish epitaxy of $\mathrm{Al}(100)$ films ${ }^{16}$ ). Next, two identical specimens, positioned on different manipulators in the UHV system, were simultaneously oxidized at $300 \mathrm{~K}$ by admitting pure oxygen gas to the chamber for a given time at a constant partial pressure, $p_{\mathrm{O}_{2}}$, of successively $1 \times 10^{-4} \mathrm{~Pa}$, $1 \times 10^{-2} \mathrm{~Pa}$, and 1.0 Pa. After each successive oxygen exposure step, the oxygen valve was closed for at least $10 \mathrm{~min}$ to reestablish UHV conditions. For one specimen, the kinetics of oxide-film growth were traced by real-time in-situ spectroscopic ellipsometry (RISE). ${ }^{6,16}$ For the other (identical) specimen, real-time in-situ substrate-curvature measurements were performed with a multi-optical stress sensor ${ }^{17,18}$ to monitor the film-force evolution (error: $\pm 0.03 \mathrm{~N} / \mathrm{m}$ ) during oxidation, while correcting for substrate curvature changes induced by the reaction of oxygen with the wafer back side. ${ }^{16,19}$

The film force change, $\Delta \tau$, due to oxygen chemisorption and oxide-film growth on the $\mathrm{Al}$ surfaces is given by

$$
\Delta \tau=\Delta\left\{\left\langle\sigma_{\mathrm{Al}}\right\rangle h_{\mathrm{Al}}+\left\langle\sigma_{\mathrm{ox}}\right\rangle h_{\mathrm{ox}}+f\right\},
$$

where the first and second term denote the change of the product of the (thickness-averaged) in-plane film stress, $\sigma_{i}$, and the film thicknesses, $h_{i}$, for the $\mathrm{Al}$ film $(i=\mathrm{Al})$ and the 
Al-oxide film $(i=\mathrm{ox})$, respectively, and the third term represents the change/appearance of the surface stress, $f$, at the $\mathrm{Al}$ and the oxide film surfaces. ${ }^{20}$ After each oxidation step, the chemical constitution, the oxide-film thickness, and the local chemical state of the ions in the oxide films were investigated in-situ by AR-XPS. ${ }^{16,21}$ Finally, the microstructure and morphology of the oxide films were characterized ex-situ by cross-sectional high-resolution transmission electron microscopy (HRTEM). ${ }^{16}$

Typical evolutions of the ellipsometric parameters, $\delta \Delta$ and $\delta \Psi$, at a central wavelength of $\lambda=589 \mathrm{~nm}$, as measured by RISE, for the step wise, cumulative oxidations of the $\mathrm{Al}(111)$ and $\mathrm{Al}(100)$ surfaces, are shown in Figs. 1(a) and 1(d), respectively. For thin dielectric films, such as $\mathrm{Al}_{2} \mathrm{O}_{3}$, the decrease of the phase shift, $\delta \Delta$, scales practically linearly with the film thickness, whereas the change of the amplitude ratio, $\delta \Psi$, is only sensitive to changes in the dipole interactions at the concerned surface. ${ }^{22}$ The observed different courses of $\delta \Psi$ at the initial stage of oxygen interaction with the bare $\mathrm{Al}(111)$ and $\mathrm{Al}(100)$ surfaces are the result of competing processes of oxygen incorporation into the subsurface and on-top oxygen chemisorption on the surface. At the initial stage of interaction of oxygen gas with bare surfaces, the rate of incorporation of $\mathrm{O}$ into the surfaces exceeds the rate of on-top chemisorption of $\mathrm{O}$ for both the $\mathrm{Al}(111)$ and the $\mathrm{Al}(100)$ surfaces, resulting in the observed, initial drop of $\delta \Psi$ (see Figs. 1(a) and 1(d) and Refs. 6 and 23-25). For the densely packed $\mathrm{Al}(111)$ surface, on-top chemisorption becomes dominant over $\mathrm{O}$ incorporation afterwards, leading to the formation of the well-established ordered $(1 \times 1)$ chemisorbed oxygen phase, ${ }^{25-27}$ as evidenced by an increase of $\delta \Psi$ (Fig. 1(a)). ${ }^{6,25}$ According to Ref. 26, with increasing oxygen exposure time islands of the $(1 \times 1)$ chemisorbed oxygen phase coalesce and gradually transform into a three dimensional, laterally closed homogeneous oxide film. For the less close-packed $\mathrm{Al}(100)$ surface, O incorporation remains promoted over $\mathrm{O}$ chemisorption and, consequently, the formation of an ordered $\mathrm{O}$ chemisorption phase is hindered. ${ }^{25,28,29}$ Indeed, only a drop of $\delta \Psi$ is observed (see Fig. $1(\mathrm{~d})$ ). As soon as the entire Al surfaces are covered with three-dimensional closed oxide layers, the value of $\delta \Psi$ becomes practically constant with increasing oxidation time (Figs. 1(a) and 1(d)). Hence, the measured courses of $\delta \Psi$ during oxidation indicate distinct differences in the mechanism of nucleation of a 3-dimensional oxide phase on the $\mathrm{Al}(111)$ and $\mathrm{Al}(100)$ surfaces: oxide nucleation on $\mathrm{Al}(111)$ proceeds from an ordered $(1 \times 1)$ chemisorbed oxygen phase, ${ }^{25,26,30}$ whereas for the more open $\mathrm{Al}(100)$ surface oxide nucleation proceeds directly from randomly incorporated $\mathrm{O}$ in the $\mathrm{Al}$ film surface. ${ }^{25,29}$

The oxide-film growth curves (at $300 \mathrm{~K}$ ), as determined by a combined approach of RISE and AR-XPS measurements, ${ }^{6,16}$ are given in Figs. 1(b) and 1(e). For every oxidation step of the $\mathrm{Al}(111)$ and $\mathrm{Al}(100)$ surfaces, each at constant $p_{\mathrm{O}_{2}}$, the oxide-film growth exhibits an initial fast growth regime, followed by a second stage with a much slower, gradually decreasing growth rate. Such passivation behavior is typical for the oxidation of Al surfaces at relatively low temperatures, as discussed above. After fast formation of a closed oxide film during the initial fast growth regime, continued oxide-film growth is rate limited by the outward transport of cations under influence of the surface charge field due to the kinetic potential. ${ }^{5-7}$ As a result of an increasing number of absorbed oxygen species with increasing $p_{\mathrm{O}_{2}}$, and thus an increasing density of electron acceptor levels for the built-up of the surface-charge field, the absolute value of the kinetic potential increases with increasing $p_{\mathrm{O}_{2}}$, which implies step-wise increase of the near-limiting oxide film thickness with step-wise increase of $p_{O_{2}}$. The limiting thicknesses approached during the slow oxidation stages at a $p_{\mathrm{O}_{2}}$ of $1 \times 10^{-4} \mathrm{~Pa}, 1 \times 10^{-2} \mathrm{~Pa}$, and $1.0 \mathrm{~Pa}$ equal $0.76 \pm 0.09 \mathrm{~nm}, 1.07 \pm 0.08 \mathrm{~nm}$, and $1.35 \pm 0.13 \mathrm{~nm}$, respectively, for the $\mathrm{Al}(111)$ surface and $0.58 \pm 0.12 \mathrm{~nm}$, $0.78 \pm 0.13 \mathrm{~nm}$, and $1.21 \pm 0.14 \mathrm{~nm}$, respectively, for the
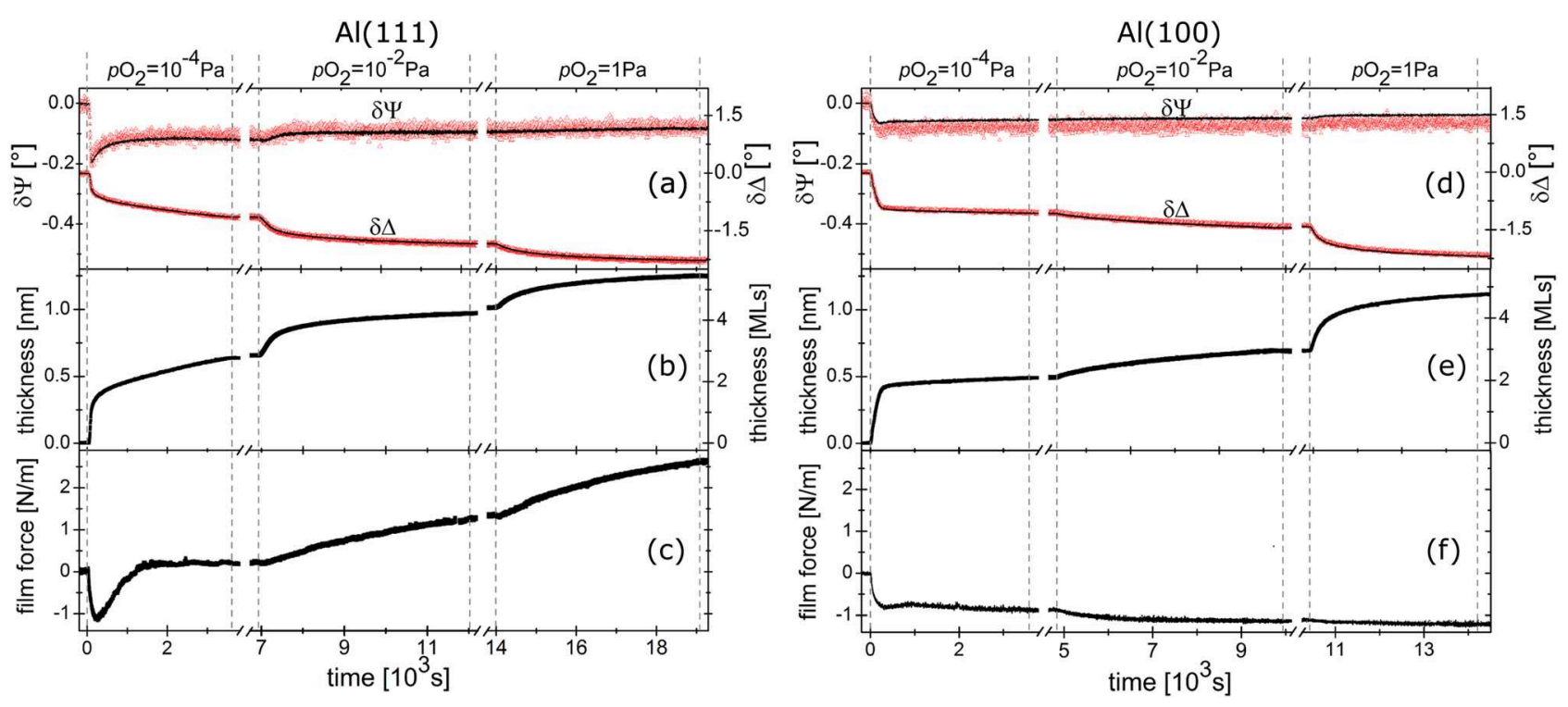

FIG. 1. Oxidation of the bare $\mathrm{Al}(111)$ and $\mathrm{Al}(100)$ surfaces as function of time at $300 \mathrm{~K}$ and at $p_{\mathrm{O}_{2}}$ of $1 \times 10^{-4} \mathrm{~Pa}, 1 \times 10^{-2} \mathrm{~Pa}$, and $1 \mathrm{~Pa}$, successively. Representative evolutions of the measured ellipsometric parameters $\delta \Psi$ and $\delta \Delta$ at $\lambda=589 \mathrm{~nm}$, as well as the result of fitting of $\delta \Psi$ and $\delta \Delta$ [(a) and (d)]; the oxide film-growth curves [(b) and (e)]; the backside-effect-corrected evolution of the change of film force [(c) and (f)]. 
$\mathrm{Al}(100)$ surface (see Figs. 1(b) and 1(e)). As revealed by AR-XPS, the increase of the near-limiting thickness is accompanied by an increase of the overall $\mathrm{O} / \mathrm{Al}$ ratio in the oxide film from $1.5 \pm 0.1$ to $1.7 \pm 0.1$; performing quantitative AR-XPS analyses as described in Ref. 21, it follows that with increasing $p_{O_{2}}$ non-stoichiometric, cation deficient oxide films develop. All of the above results for the room-temperature oxidation of $\mathrm{Al}(111)$ and $\mathrm{Al}(100)$ film surfaces are in excellent agreement with previous studies on the thermal oxidation of $\mathrm{Al}(111)$ and $\mathrm{Al}(100)$ bulk single crystals. ${ }^{6,7,21}$

The time evolutions of the film force (at $300 \mathrm{~K}$ ) are shown in Figs. 1(c) and 1(f). The film-force evolutions, $\Delta \tau$, also (i.e., as for the course of $\delta \Psi$; see above) strongly depend on the $\mathrm{Al}$ surface orientation. Oxidation of the $\mathrm{Al}(111)$ surface commences, at $p_{O_{2}}=1 \times 10^{-4} \mathrm{~Pa}$, with an instantaneous compressive film-force change to a minimum value of $-1.2 \mathrm{~N} / \mathrm{m}$ at $t \approx 230 \mathrm{~s}$ (Fig. 1(c)). The film force subsequently increases to $+0.2 \mathrm{~N} / \mathrm{m}$, thus becoming tensile. Continued oxide-film growth during the following oxygen exposure steps leads to an increase of the (tensile) film force to $1.3 \mathrm{~N} / \mathrm{m}$ at $p_{O_{2}}=1 \times 10^{-2} \mathrm{~Pa}$ (thickness $=1.0 \mathrm{~nm}$ ) and $2.6 \mathrm{~N} / \mathrm{m}$ at $p_{O_{2}}=1.0 \mathrm{~Pa}$ (thickness $=1.3 \mathrm{~nm}$ ). As for the $\mathrm{Al}(111)$ surface, oxidation of the $\operatorname{Al}(100)$ surface at $p_{O_{2}}=1 \times 10^{-4} \mathrm{~Pa}$ results in an instantaneous compressive film-force change; in this case the film force equals $-0.8 \mathrm{~N} / \mathrm{m}$ after $t \approx 350 \mathrm{~s}$ (Fig. 1(f)). However, in contrast with the $\mathrm{Al}(111)$ surface, during the following oxygen exposure steps at $p_{O_{2}}=1 \times 10^{-2} \mathrm{~Pa}$ and $p_{O_{2}}=1.0 \mathrm{~Pa}$ the film force remains almost constant with a final (compressive) value of $-1.1 \mathrm{~N} / \mathrm{m}$. Noteworthy, for both Al surfaces, no changes of the film force are observed upon interruption of the oxygen exposure at any stage of oxidation ${ }^{16}$ (see Figs. $1(\mathrm{c})$ and $1(\mathrm{f}))$.

Cross-sectional HRTEM micrographs of the oxide films, as formed on the Al surfaces after the successive oxygen exposure steps up to 1.0 Pa, are shown in Fig. 2. Evidently, the developing oxide films on $\mathrm{Al}(111)$ and $\mathrm{Al}(100)$ surfaces are both amorphous and have uniform thicknesses of $1.3 \pm 0.1 \mathrm{~nm}$ and $1.2 \pm 0.1 \mathrm{~nm}$, respectively, in accordance with the thickness values determined by AR-XPS. Noteworthy, careful

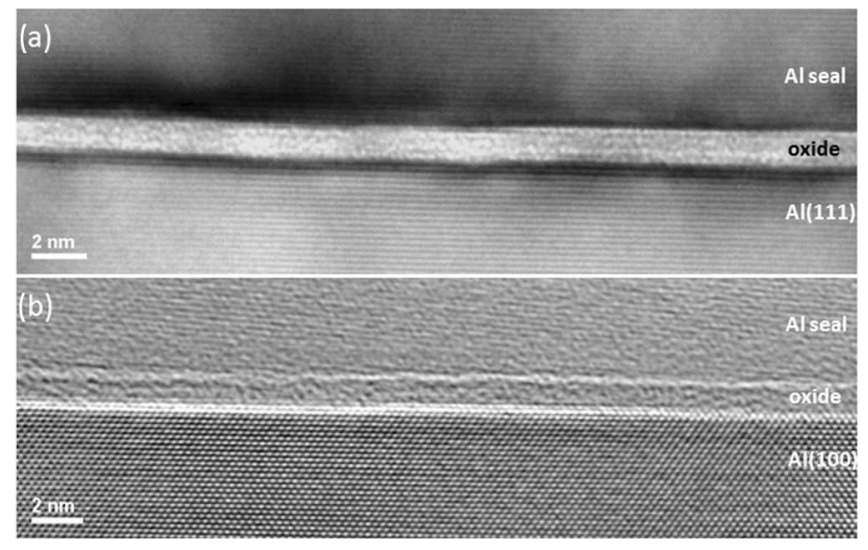

FIG. 2. Cross-sectional HRTEM micrographs of the amorphous $\mathrm{Al}_{2} \mathrm{O}_{3}$ oxide film formed on (a) the $\mathrm{Al}(111)$ film surface and (b) the $\mathrm{Al}(100)$ film surface, after successive oxygen gas exposures at $p_{\mathrm{O}_{2}}=1 \times 10^{-4} \mathrm{~Pa}, p_{\mathrm{O}_{2}}$ $=1 \times 10^{-2} \mathrm{~Pa}$, and $p_{O_{2}}=1 \mathrm{~Pa}$ at $300 \mathrm{~K}$ (see Fig. 1). inspections of the recorded HRTEM micrographs suggests that the oxide films on $\mathrm{Al}(111)$ have a higher degree of medium-range order: compare Figs. 2(a) and 2(b) (see also discussion further below).

The contrasting film-force evolutions of the developing oxide films on $\mathrm{Al}(111)$ and $\mathrm{Al}(100)$ can be rationalized, considering the differences in the microstructural evolutions of both am- $\mathrm{Al}_{2} \mathrm{O}_{3}$ films, as follows. The bare $\mathrm{Al}(111)$ and $\mathrm{Al}(100)$ surfaces intrinsically exhibit a tensile surface stress as a consequence of the spilling-out of electrons from the surface into the vacuum. ${ }^{33,34}$ The initial incorporation of $\mathrm{O}$ into the $\mathrm{Al}$ subsurface (see above) reduces the spilling-out of electrons from the metal surfaces ${ }^{35}$ and causes a volume expansion of the subsurface region. Consequently, compressive stress components parallel to the surface are induced in the $\mathrm{Al}$ surface regions at the onset of oxygen exposure (Figs. 1(c) and 1(f)). A significantly higher instantaneous compressive surface stress component is generated upon oxygen incorporation into the bare $\mathrm{Al}(111)$ surface, which is a direct consequence of the higher atomic density of the $\mathrm{Al}(111)$ surface, as compared to the more open $\mathrm{Al}(100)$ surface. The stress induced in the subsurface region by a surface-area fraction incorporated $\mathrm{O}$ into each $\mathrm{Al}$ surface can be estimated from the measured (linear) decrease of the film force and the experimental linear oxidation rate regime ${ }^{36}$ at the onset of oxidation (i.e., for oxide thicknesses $<2.3 \AA$ ). Thus, the estimated surface stress contribution by incorporated $\mathrm{O}$ atoms equals $-1.5 \pm 0.6 \mathrm{~N} / \mathrm{m}$ for $\mathrm{Al}(111)$ and $-0.4 \pm 0.1 \mathrm{~N} / \mathrm{m}$ for $\mathrm{Al}(100)$ (each result is the average of three measurements, employing atomic densities of $1.41 \times 10^{19} \mathrm{~m}^{-2}$ and $1.22 \times 10^{19} \mathrm{~m}^{-2}$ for the $\mathrm{Al}(111)$ and $\mathrm{Al}(100)$ surfaces $^{25}$ and taking the average number of $\mathrm{O}$ atoms per unit volume equal to the value of $a m-\mathrm{Al}_{2} \mathrm{O}_{3}$ (i.e., $5.62 \times 10^{28} \mathrm{~m}^{-3}$ (Ref. 37))).

In case of the $\mathrm{Al}(111)$ surface, after the development of instantaneous compressive surface stress at the very beginning of $\mathrm{O}$ interaction (as discussed above), on-top $\mathrm{O}$ adsorption becomes dominant over oxygen incorporation and an ordered $(1 \times 1)$-O chemisorption phase is formed (which is associated with an increase of the ellipsometric parameter $\Psi$; see above discussion). As a result of the predominant on top surface adsorption of electronegative oxygen atoms at this stage of oxygen exposure, the electron depletion of the $\mathrm{Al}(111)$ surface is enhanced and thus a distinct tensile stress component is induced into the $\mathrm{Al}$ subsurface region (see Figs. 1(a) and 1(c)). ${ }^{35}$

In the case of the $\mathrm{Al}(100)$ surface, after the formation of a laterally closed oxide film, no significant change in the film force is observed during continued growth (thickening) of the $a m-\mathrm{Al}_{2} \mathrm{O}_{3}$ film (Fig. 1(f)). The successive increments of $p_{\mathrm{O}_{2}}$ led to a step-wise thickening of the oxide film on $\mathrm{Al}(100)$, but no growth stress evolved. On the contrary, a significant tensile stress development takes place exclusively during thickening of the $a m-\mathrm{Al}_{2} \mathrm{O}_{3}$ film on $\mathrm{Al}(111)$ (no stress relaxations are observed upon interruption of the oxygen exposure; ${ }^{16}$ see Fig. 1(c)). Obviously, the observed strikingly different film force evolutions upon thickening of the amorphous oxides on $\mathrm{Al}(111)$ and $\mathrm{Al}(100)$ cannot be ascribed to adsorption-induced changes of surface stress. Moreover, also the oxide growth mechanism itself, which for both $\mathrm{Al}$ surfaces involves outward transport of $\mathrm{Al}$ cations through the 
oxide film under influence of the surface-charge field (see above), ${ }^{6}$ cannot account for the different film-force evolutions. Since self-diffusion of $\mathrm{Al}$ at $300 \mathrm{~K}$ is too slow $^{38}$ to enable significant diffusion of oxidation-induced vacancies into the bulk of the Al films, any oxidation-induced vacancies in the $\mathrm{Al}$ substrates are most likely annihilated at the metal/ oxide interface (cf. Ref. 4). This leads to a reduction of the nominal $\mathrm{Al}$ film thicknesses of up to about $0.9 \mathrm{~nm}$ (as estimated on the basis of the near-limiting oxide-film thickness attained at 1.0 Pa; see Figs. 1(b) and 1(e)). The resulting film-force contribution due to the reduction of the Al film thickness (while the thickness-averaged $\mathrm{Al}$ film stress remains constant) is of similar, practically negligible, magnitude (less than $-0.2 \mathrm{~N} / \mathrm{m}$ ) for both $\mathrm{Al}$ surfaces and therefore cannot explain the strikingly different stress evolutions. Hence, it is concluded that $a m-\mathrm{Al}_{2} \mathrm{O}_{3}$ films formed on $\mathrm{Al}(100)$ are stress free, whereas intrinsic tensile stresses are generated in the $a m-\mathrm{Al}_{2} \mathrm{O}_{3}$ films formed on $\mathrm{Al}(111)$. As discussed below, the different stress evolutions originate from the different microstructural developments in the $a m-\mathrm{Al}_{2} \mathrm{O}_{3}$ films on $\mathrm{Al}(111)$ and $\mathrm{Al}(100)$.

The am- $\mathrm{Al}_{2} \mathrm{O}_{3}$ films formed on $\mathrm{Al}(111)$ and $\mathrm{Al}(100)$ can be described as constituted of neighboring "building blocks" of edge- and corner-sharing $\left[\mathrm{AlO}_{4}\right],\left[\mathrm{AlO}_{5}\right]$, and $\left[\mathrm{AlO}_{6}\right]$ polyhedra (with the $\mathrm{Al}$ cations in, respectively, tetrahedral, pentagonal, and octahedral interstices of the distorted, densely packed oxygen sublattice), ${ }^{39-41}$ where the free volume is associated with vacancy-type defects. ${ }^{42}$ Although the oxide films on $\mathrm{Al}(111)$ and $\mathrm{Al}(100)$ are both amorphous according to the HRTEM analysis, local chemical state analysis by XPS revealed strikingly different microstructural developments for the evolving oxide films on the two $\mathrm{Al}$ surfaces. ${ }^{16}$ On $\mathrm{Al}(100)$, the electronic polarizabilities around the core-ionized $\mathrm{Al}$ and $\mathrm{O}$ ions remain practically constant with increasing thickness, which evidences that the local chemical environments of the constituent $\mathrm{Al}$ and $\mathrm{O}$ ions is practically constant during growth. For the $\mathrm{Al}(111)$ surface, the local chemical environment of $\mathrm{O}$ anions also remains constant during oxide-film growth. However, the local chemical environment of $\mathrm{Al}$ cations shows a pronounced change (i.e., a considerable increase of the local polarizability) with increasing film thickness, suggesting an increase of free volume in the oxide film during growth. ${ }^{31,32}$ The increasing cation deficiency for the thickening oxide films on $\mathrm{Al}(111)$ (see above) is compatible with such an overall increase of the free volume (i.e., increase of cation vacancies). It is concluded that, for the oxidation of the $\mathrm{Al}(111)$ surface, additional free volume (cation vacancies) is continuously added to the thickening oxide. In the absence of structural relaxation during film growth, the continuous generation of free volume (and its associated tendency for shrinkage of the surrounding "lattice") results in the measured build-up of a tensile stress component in the developing $a m-\mathrm{Al}_{2} \mathrm{O}_{3}$ film on $\mathrm{Al}(111)$. The kinetic hindrance of structural relaxation processes during oxide-film growth is presumably inherited from the ordered $(1 \times 1)^{25,26}$ oxygen phase as formed during the initial stage of $\mathrm{O}$ interaction with the bare $\mathrm{Al}(111)$ surface, resulting in a more restricted alignment of neighboring "building blocks" in the amorphous oxide film on $\mathrm{Al}(111){ }^{30}$ No such ordered $\mathrm{O}$ phase occurs upon oxidation of
$\mathrm{Al}(100) .{ }^{25,29}$ Indeed, as evidenced from the XPS chemical state analysis, for the $\mathrm{Al}(100)$ surface, the generation of free volume due to the formation of cation vacancies can be annihilated by structural relaxation processes (i.e., rearrangement of the building blocks, as observed in MD simulations ${ }^{43,44}$ ). As a result, developing intrinsic tensile stress can be largely relaxed, resulting in stress-free amorphous oxide films on $\mathrm{Al}(100)$. Summarizing, structural relaxation during oxide-film growth on $\mathrm{Al}(100)$ is more pronounced than on $\mathrm{Al}(111)$. This is consistent with the present HRTEM analysis hinting at a higher degree of medium-range order (i.e., a more restrict alignment of the [AlO] building blocks) in the developing oxide films on $\mathrm{Al}(111)$ than in those on $\mathrm{Al}(100)$.

In conclusion, the present study demonstrates that pronounced intrinsic stresses can be generated in ultrathin amorphous $\mathrm{Al}_{2} \mathrm{O}_{3}$ films formed by thermal oxidation of bare $\mathrm{Al}$ surfaces at low temperatures. The magnitude of the stress strongly depends on the Al surface orientation: Oxide films formed on $\mathrm{Al}(100)$ are stress free, whereas oxide films formed on $\mathrm{Al}(111)$ exhibit a thickness averaged in-plane tensile film stress as large as $1.9 \mathrm{GPa}$. The striking dependence of stress evolution on the Al surface orientation is the result of adsorption induced changes of surface stress at the very beginning of oxygen exposure, and competing processes of free volume generation and structural relaxation during continued oxide-film growth.

The authors are grateful to U. Salzberger for the preparation of the TEM foils, to P. Kopold for HRTEM investigation and Dr. F. Phillipp for invaluable discussion.

${ }^{1}$ V. V. Afanas'ev and A. Stesmans, J. Appl. Phys. 102, 081301 (2007).

${ }^{2}$ U. Diebold, S.-C. Li, and M. Schmid, Annu. Rev. Phys. Chem. 61, 129 (2010).

${ }^{3}$ J. Ma, Y. He, D. Wang, and W. Gao, Mater. Lett. 58, 807 (2004).

${ }^{4}$ N. Cabrera and N. F. Mott, Rep. Prog. Phys. 12, 163 (1949).

${ }^{5}$ A. T. Fromhold and E. L. Cook, Phys. Rev. 158, 600 (1967).

${ }^{6}$ F. Reichel, L. P. H. Jeurgens, and E. J. Mittemeijer, Acta Mater. 56, 2897 (2008).

${ }^{7}$ N. Cai, G. Zhou, K. Müller, and D. E. Starr, Phys. Rev. Lett. 107, 035502 (2011).

${ }^{8}$ F. Reichel, L. P. H. Jeurgens, and E. J. Mittemeijer, Acta Mater. 56, 659 (2008).

${ }^{9}$ L. P. H. Jeurgens, Z. Wang, and E. J. Mittemeijer, Int. J. Mater. Res. 100, 1281 (2009).

${ }^{10}$ N. Cai, G. Zhou, K. Müller, and D. E. Starr, J. Phys. Chem. C 117, 172 (2013).

${ }^{11}$ A. G. Revesz and F. P. Fehlner, Oxid. Met. 15, 297 (1981).

${ }^{12}$ L. P. H. Jeurgens, F. Reichel, S. Frank, G. Richter, and E. J. Mittemeijer, Surf. Interface. Anal. 40, 259 (2008).

${ }^{13}$ F. N. Rhines and J. S. Wolf, Metall. Trans. 1, 1701 (1970).

${ }^{14}$ D. R. Clarke, Acta Mater. 51, 1393 (2003).

${ }^{15}$ X. Dong, X. Feng, and K.-C. Hwang, J. Appl. Phys. 112, 023502 (2012).

${ }^{16}$ See supplementary material at http://dx.doi.org/10.1063/1.4867471 for specific information on the experimental procedures, chemical state analysis, and additional film force measurements.

${ }^{17}$ E. Chason and B. W. Sheldon, Surf. Eng. 19, 387 (2003).

${ }^{18}$ D. Flötotto, Z. M. Wang, L. P. H. Jeurgens, E. Bischoff, and E. J. Mittemeijer, J. Appl. Phys. 112, 043503 (2012).

${ }^{19}$ D. Flötotto, Z. M. Wang, L. P. H. Jeurgens, and E. J. Mittemeijer, J. Appl. Phys. 115, 23501 (2014).

${ }^{20}$ S. Suresh and L. B. Freund, Thin Film Materials (Cambridge University Press, Cambridge, England, 2003).

${ }^{21}$ F. Reichel, L. P. H. Jeurgens, G. Richter, and E. J. Mittemeijer, J. Appl. Phys. 103, 093515 (2008).

${ }^{22}$ R. M. Azzam, Ellipsometry and Polarized Light (Amsterdam, NorthHolland, 1979). 
${ }^{23}$ P. Hofmann, W. Wyrobisch, and A. M. Bradshaw, Surf. Sci. 80, 344 (1979). ${ }^{24}$ J. Grimblot and J. M. Eldridge, J. Electrochem. Soc. 129, 2366 (1982).

${ }^{25}$ I. P. Batra and L. Kleinman, J. Electron Spectrosc. Relat. Phenom. 33, 175 (1984).

${ }^{26}$ H. Brune, J. Wintterlin, J. Trost, G. Ertl, J. Wiechers, and R. J. Behm, J. Chem. Phys. 99, 2128 (1993).

${ }^{27}$ F. Soria, V. Martínez, M. C. Muñoz, and J. L. Sacedón, Phys. Rev. B 24, 6926 (1981).

${ }^{28}$ M. L. den Boer, T. L. Einstein, W. T. Elam, R. L. Park, L. D. Roelofs, and G. E. Laramore, Phys. Rev. Lett. 44, 496 (1980).

${ }^{29}$ S. A. Larson and L. L. Lauderback, Surf. Sci. 284, 1 (1993).

${ }^{30}$ C. Lanthony, J. M. Ducere, M. D. Rouhani, A. Hemeryck, A. Esteve, and C. Rossi, J. Chem. Phys. 137, 094707 (2012).

${ }^{31}$ R. A. B. Devine and T. Busani, Appl. Phy. Lett. 86, 062902 (2005).

${ }^{32}$ J. Arndt, R. A. B. Devine, and A. G. Revesz, J. Non-Cryst. Solids 131-133, 1206 (1991).

${ }^{33}$ W. Jun, Y. L. Fan, D. W. Gong, S. G. Shen, and X. Q. Fan, Modell. Simul. Mater. Sci. Eng. 7, 189 (1999).
${ }^{34}$ R. J. Needs, Phys. Rev. Lett. 58, 53 (1987).

${ }^{35}$ P. J. Feibelman, Phys. Rev. B 56, 2175 (1997).

${ }^{36}$ At the initial stage of oxygen interaction with the Al surfaces the fraction incorporated oxygen increases linearly with time, since the number of absorbed oxygen atoms at the parent $\mathrm{Al}$ surfaces is only determined by the constant amount of oxygen atoms supplied from the gas phase and the constant sticking coefficients of the concerned surfaces.

${ }^{37}$ W. J. Bernard and J. W. Cook, J. Electrochem. Soc. 106, 643 (1959).

${ }^{38}$ J. Burke and T. Ramachan, Metall. Trans. 3, 147 (1972).

${ }^{39}$ G. Gutiérrez and B. Johansson, Phys. Rev. B 65, 104202 (2002).

${ }^{40}$ S. K. Lee, S. B. Lee, S. Y. Park, Y. S. Yi, and C. W. Ahn, Phys. Rev. Lett. 103, 095501 (2009).

${ }^{41}$ P. Lamparter and R. Kniep, Phys. B 234-236, 405 (1997).

${ }^{42}$ K. G. Lynn, Phys. Rev. Lett. 44, 1330 (1980).

${ }^{43}$ A. Hasnaoui, O. Politano, J. M. Salazar, and G. Aral, Phys. Rev. B 73, 035427 (2006).

${ }^{44}$ T. Campbell, R. K. Kalia, A. Nakano, P. Vashishta, S. Ogata, and S. Rodgers, Phys. Rev. Lett. 82, 4866 (1999). 